\title{
The Cost of Disability for Indigenous People: A Systematic
}

\section{Review}

\author{
Ali Lakhani \\ Menzies Health Institute Queensland \\ The Hopkins Centre, Griffith University \\ Jennifer Cullen \\ Synapse \\ Clare Townsend \\ Synapse
}

\section{Abstract}

It is expected that Indigenous people experience asymmetric disability costs compared to non-Indigenous people. No systematic review has investigated the cost of disability for Indigenous people. A systematic review can contribute to the evidence base and inform the health and social care services that Indigenous people with disability receive. Thus, this systematic review aimed to: (i) provide insight into the distinct cost of disability for Indigenous people and (ii) summarise the current state of knowledge concerning the cost of disability for Indigenous people. The PRISMA approach was applied and four databases - MEDLINE, ISI Web of Science, CINAHL and ProQuest Social Sciences - were searched for peer-reviewed literature published before January 2017. After a removal of duplicates, the titles of 193 sources were reviewed against the inclusion criteria. Of these, eight sources were considered for a full-text review. After a full-text review, zero sources met the entire inclusion criteria. While these eight studies did not entirely meet search criteria, findings from two studies closely met the review criteria and provided insight into service considerations that may contribute to distinct costs of disability for Indigenous people. These considerations include: i) providing culturally appropriate assessments and psychometric tools for the identification and monitoring of disability, (ii) ensuring healthcare and service provider cultural training, (iii) raising community awareness around disability services, (iv) delivering holistic integrated health-care models offered locally, and (v) building relationships with families. Irrespective of these considerations, the paucity of research in the area makes it impossible clarify the cost of disability for Indigenous people. Consequently, the need for research in this area is paramount. It is imperative that future research considers the distinct costs of providing health and social care services for Indigenous people with disability. This research will favourably inform health and social care services offered to Indigenous people with disability, and furthermore contribute towards positive health and wellbeing outcomes.

Keywords: community, Indigenous people, disability, cost, self-management, systematic review 
Cost of disability data across the developed world is limited (World Health Organisation [WHO], 2011; Antón, Braña. \& Muñoz de Bustillo, 2016). As a result there is limited understanding surrounding the distinct costs of disability for Indigenous and nonIndigenous people. The gap in research is likely due to: (i) differing definitions of disability across disciplines (WHO, 2011, Antón et al., 2016), (ii) limited data concerning service costs (WHO, 2011), and (iii) the need of data from various disciplines (WHO, 2011). Accordingly, various methods have been used to measure the cost of disability however, there is no definitive universally recognised methodology to measure disability cost (WHO, 2011; Antón et al., 2016). For example, disability cost has been measured through the loss of employment earnings among people with disability and their families (Berthoud, 1991; Sen, 2004; Doran, Einfeld, Madden, Otim, Horstead, Ellis, \& Emerson, 2012), the cost of healthcare treatment (Berthoud, 1991; Brouwer, Rutten, \& Koopmanschap, 2001), and the extra costs incurred by those with disability to maintain a reasonable standard of living (Berthoud, 1991; Sen, 2004). Doran et al. (2012) indicates that the cost of disability also includes the cost of publically provided welfare and education services, and family expenditure on health and social care. While numerous methods to identify the cost of disability exist, approaches have been critiqued for not considering the pain and suffering and the loss of community participation experienced by individuals with disability and their families (Doran et al., 2012).

Furthermore, the World Health Organisation's report, World Report on Disability (hereafter the Report) (2011), is a seminal document, which aims to provide '...evidence for innovative policies and programmes that can improve the lives of people with disabilities' (p. xi). The Report clarifies that a variety of methods can be used to estimate the cost of disability and these costs are characterised as either direct or indirect. Direct costs are considered (i) added costs that people with disability incur to achieve a reasonable standard of living, and (ii) government organised disability benefits received via cash and/or in-kind work. Indirect costs are considered (i) the loss of labour as a result of disability, and subsequent tax contribution, and (ii) social isolation and stress. Clearly, the cost of disability has both financial and non-financial components, which require consideration. It is important that these costs are investigated empirically, as the measurement and estimation of the cost of disability has impact on the health and social care services that people with disability receive (WHO, 2011).

\section{Factors contributing to the cost of disability for Indigenous people}

Indigenous people throughout the developed world achieve optimal health outcomes through the provision of distinct health and social care services, and experience unique health determinants (see Reading, Kmetic, \& Gideon, 2007; Reading \& Wien 2009; DiGiacomo, Delaney, Abbott, Davidson, Delaney, \& Vincent, 2013b; Purdie, Dudgeon, \& Walker, 2010). Consequently, it is expected that Indigenous people with disability require distinct services that address unique health determinants. For example, in terms of service provision, Elder (2013) utilised a wānanga (a forum for learning and discussion) among Māori community members and Elders to establish an intervention for young people who have experienced traumatic brain injury. The resulting intervention, Te Waka Oranga, is described as a culturally appropriate framework, which requires that the family and the young person with traumatic brain injury work in collaboration with clinicians, towards shared health goals. In terms of the determinants of health, Durst et al.'s (2006) Canadian report, Urban aboriginal families of children with disabilities: social inclusion or exclusion and the Productivity Commission's (2011) Australian report, Disability Care and Support both clarify that the utilisation of disability services by 
Indigenous people in both contexts have been impeded by their mistrust of the health care and governing systems. This mistrust has been attributed to the legacy of colonisation underpinned by a longstanding history of Indigenous children being separated from their families.

Contributions towards the cost of disability for Indigenous people can be inferenced from research investigating the delivery of diverse health services among Indigenous people. In terms of health services, research has established that distinct culturally appropriate health and wellbeing services are essential towards ensuring Indigenous peoples' health and wellbeing (DiGiacomo et al., 2013b; Purdie et al., 2010). Health services employing a western biomedical focus are often unable to adequately meet the health and social care needs of Indigenous people (Haynes, Taylor, Durey, Bessarab, \& Thompson, 2014), and address the distinct determinants that impact Indigenous peoples' health (Avery, 2016). Such services have the potential to be discriminatory, and inadequately consider the culture and language of Indigenous clients (Isaacs, Pyett, Oakley-Browne, Gruis, \& Waples-Crowe, 2010). Whereas, models of care, which build on Indigenous understandings of wellbeing, for example spiritual wellbeing, have been identified as effective towards favourably impacting the health of Indigenous people (Purdie et al., 2010).

Consequently, Indigenous designed health services, or co-designed health services which include both Indigenous and non-Indigenous health professionals are expected to contribute towards better health outcomes among Indigenous people (Durey, Wynaden, Thompson, Davidson, Bessarab, \& Katzenellenbogen, 2012). In this regard, previous research has established that Indigenous determined health services provide higher levels problem management for patients (Larkins, Geia, \& Panaretto, 2006), and general practitioners within these settings perform at a higher level (Panaretto, Wenitong, Button, \& Ring, 2014) when compared to mainstream services. These services are distinct, and are likely underpinned by distinct costs.

Across the developed world a high proportion of Indigenous people reside in remote communities (Government of Canada [GOC], 2011; Biddle, Al-Yaman, Gourley et al., 2012), where conventional models of care are often ineffective (Avery, 2016). In Australia, recent estimates suggest that approximately $18 \%$ of Indigenous people requiring assistance with core activities reside in remote/very remote areas (Biddle, AlYaman, Gourley, Gray, Bray, Brady, ... \& Montaigne, 2014). The remote location of some Indigenous people can impact the cost of services offered (DiGiacomo et al., 2013), where for the most part, the cost of offering health and social support in remote areas is higher than in non-remote areas (Biddle et al., 2012; Dew, Bulkeley, Veitch et al., 2013; DiGiacomo et al., 2013; Mitchell, 2015).

Irrespective of location, the costs of offering services to Indigenous populations can be higher than non-Indigenous people. For example, the Australian Government Commonwealth Grants Commission 2014, Report on GST Revenue Sharing Relativities, (Australian Government, 2014) elucidates some of the costs of providing public services to Aboriginal and/or Torres Strait Islander people in Australia. Within the Report, the average cost of community health, and patient admissions were reported higher for Aboriginal and/or Torres Strait Islander people $(\$ 1,927$ and $\$ 2,866$ per person respectively) compared to non-Aboriginal and/or Torres Strait Islander people (\$923 and $\$ 1,225$ per person respectively). These findings provide evidence to the notion that 
Indigenous people face asymmetric health care costs compared to those who are nonIndigenous, and that these costs may be higher.

\section{The current study}

Given the distinct nature of health and social care services required to ensure favourable health outcomes among Indigenous people, and the discrete health determinants impacting the health and wellbeing of Indigenous people, it is expected that Indigenous people face a unique cost of disability, which differs from non-Indigenous people. As the measurement and estimation of the cost of disability directly impacts the health and social care programs offered to people with disability (WHO, 2011), it is important to consider the cost of disability for Indigenous people.

Synapse is an Australian organisation providing support and advocacy for people with neurocognitive disability, particularly Aboriginal and/or Torres Strait Islander people. Australia is currently transitioning to a self-directed model of disability service provision where people with disability will have direct control over the resources used for their health and social support (see Parliament of Australia, 2013). As a result, it is important to consider the cost of disability for Indigenous people throughout the developed world as this may provide insight into the disability costs for Aboriginal and/or Torres Strait Islander people in Australia.

Therefore, a systematic review was undertaken to identify the cost of disability for Indigenous people throughout the developed world. The review aimed to: (i) provide insight into the distinct cost of disability for Indigenous people and (ii) summarise the current state of knowledge concerning the cost of disability for Indigenous people.

\section{Method}

The PRISMA approach (Moher, Liberati, Tetzlaff, Altman, Group, \& for the P.G., 2009) to undertaking a systematic review was employed.

\section{Search Strategy}

On $17^{\text {th }}$ January 2017 the databases MEDLINE, ISI Web of Science, CINAHL and ProQuest Social Sciences were searched from the Griffith University Online Library. The suggested databases were searched for research published any date using the search string: ("Aboriginal"” OR "Torres Strait" OR "First Nation"” OR "First People*" OR "Indigenous" OR "Native*" OR "Māori" OR "Inuit" OR "Eskimo" OR "Koori"” OR "Murri" OR "ATSI" OR "American Indian") AND Disab* AND (Cost* or Burden). Search information details are included in Table 1 below. 
Table 1: Search details

\begin{tabular}{l|l|l|l}
\hline Database & Date & Search & Findings \\
\hline MEDLINE & $17-01-17$ & All text & 129 \\
Web Of Science & $17-01-17$ & Topics & 120 \\
CINAHL & $17-01-17$ & Title \& Abstract & 41 \\
ProQuest Social Science & $17-01-17$ & Title \& Abstract & 9 \\
\hline
\end{tabular}

\section{Eligibility}

To be included in this review identified studies were required to meet a set of criteria. Each publication was required to be (i) peer-reviewed, (ii) published in English, (iii) include a participant population of Indigenous people from the developed world (iv) and consider the cost of disability. Two types of manuscripts were considered: original research articles and systematic reviews. Studies, which focused on the 'burden of disability', were also included for review given the potential that they may have also investigated disability cost for Indigenous people. Furthermore, studies, which included a sample population combining Indigenous and non-Indigenous people, were also considered subject to their inclusion of separate findings concerning the cost of disability for Indigenous people.

\section{Screening and study selection}

All citations identified from database searches were downloaded into an Endnote library. Initially duplicates were removed, and after, the titles, abstracts and full-texts of articles were reviewed against the inclusion criteria. The first author reviewed each citation against the inclusion criteria. If uncertain about the inclusion or exclusion of a source, a consensus was reached among the three authors.

\section{Findings}

The screening process is detailed in Figure 1. A search of four databases provided 299 articles for review. After removing 106 duplicates, 193 articles remained for the title assessment stage. The titles of these articles were reviewed and 179 excluded, as they did not meet the inclusion criteria. After, the abstracts of the remaining 14 articles were reviewed; six of these did not meet the inclusion criteria and were subsequently removed. Consequently, the full-texts of eight sources were reviewed against the inclusion criteria. While these sources included Indigenous populations they were excluded, as they did not focus on cost of disability. The eight excluded studies concerned: cost-effectiveness of health care interventions (Angell, Muhunthan, Irving, Eades, \& Jan, 2014), healthcare preferences of Elders and care workers (Browne, Mokuau, Ka'opua, Kim, Higuchi, \& Braun, 2014), identification and prevention of disability, and service access (DiGiacomo et al., 2013), experiences of parents and carers in accessing disability support services for their child(ren) (Green, Abbott, Delaney, Patradoon-Ho, Delaney, Davidson, \& DiGiacomo, 2016), post-injury outcomes (Maclennan, Wyeth, Davie, Wilson, \& Derrett, 2014), and burden of disease and injury (Zhao, Guthridge, Magnus, \& Vos, 2004; Vos, Barker, Begg, Stanley, \& Lopez, 2009; Zhao, Condon, Guthridge, \& You, 2010). 
Figure 1: Article selection process

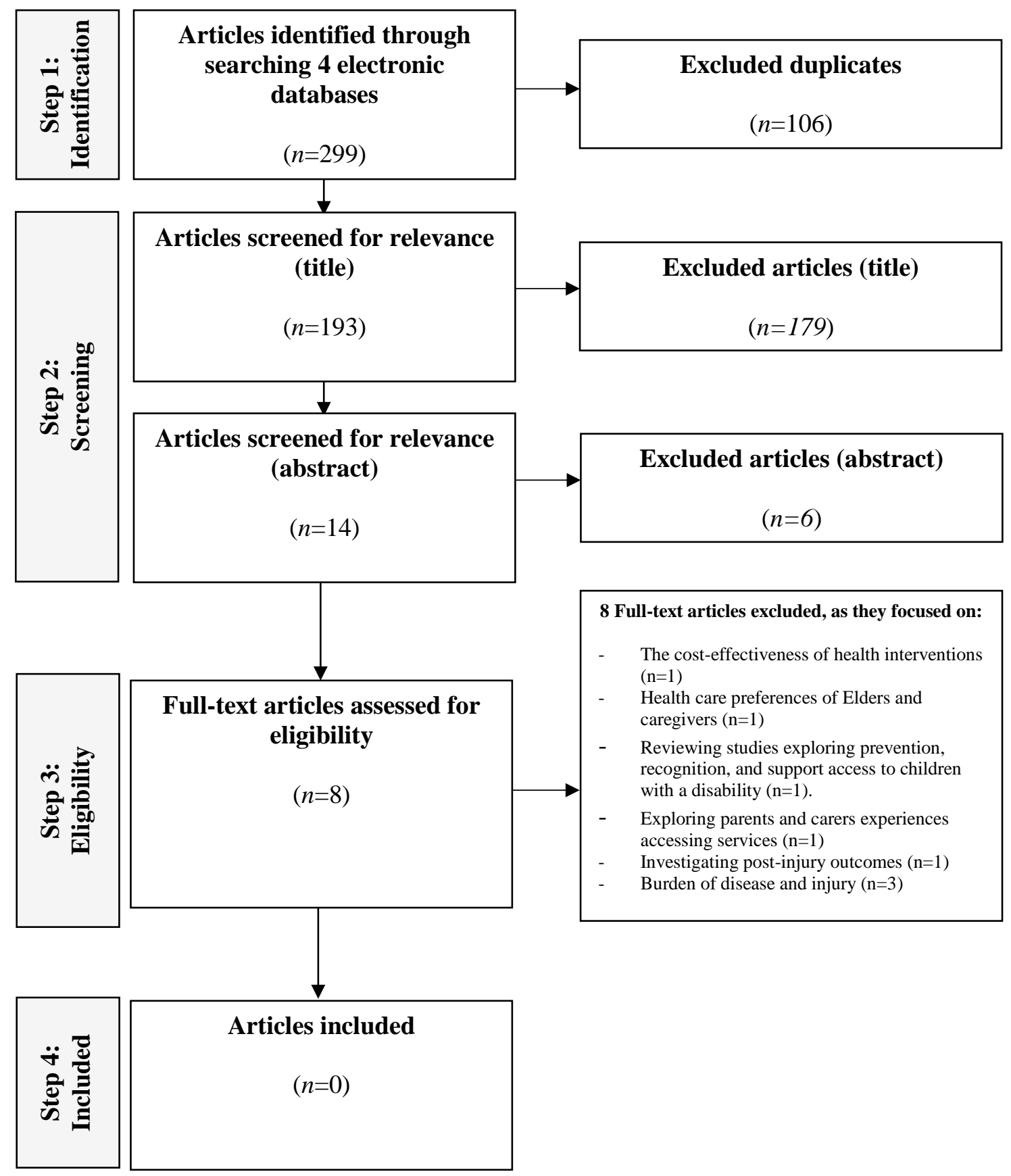




\section{Discussion}

This systematic review aimed to synthesise research investigating the cost of disability for Indigenous people and found that no peer-reviewed research exists. A review of four databases provided zero studies that entirely met the selection criteria. Consequently, this review provides evidence to the argument that limited economic health research particular to Indigenous people has been conducted (Angell et al., 2014). Previously Angell et al. (2014) conducted a systematic review which aimed to present the current state of knowledge surrounding cost-effective health interventions for Indigenous people. Nineteen studies met their inclusion criteria (zero focusing on disability). Given limited studies in the area, Angell et al. (2014) were forced to conclude that it is not possible to definitively suggest key characteristics of cost-effective health interventions for Indigenous people. Similarly, the current review has found that there are no peerreviewed studies to inform our understanding concerning the cost of disability for Indigenous people.

While there were zero studies that directly focused on investigating the cost of disability for Indigenous people, eight studies closely met the selection criteria and were subject to a full text review. It is worthwhile to consider the findings from two of these studies as they provide insight into factors that may contribute to distinct disability costs for Indigenous people (see DiGiacomo et al., 2013; Green et al., 2016). Specifically, these studies concerned disability service provision and the considerations identified throughout these two studies can inform a subsequent approach to measure disability cost among Indigenous people.

DiGiacomo et al. (2013) conducted a narrative review to identify the factors impacting the identification and prevention of disability, and health care service utilisation, for Aboriginal and/or Torres Strait Islander children with disability in Australia. The authors identified a variety of factors that are important to consider concerning health care utilisation among Aboriginal and/or Torres Strait Islander children with disability in Australia. These factors include: (i) culturally appropriate assessments and psychometric tools for the identification and monitoring of disability, (ii) healthcare and service provider cultural training, and (iii) building relationships with families. These important factors are likely to result in distinct costs for Indigenous disability service provision, and further should be accounted for when attempting to measure the cost of disability for Indigenous people.

Green et al. (2016) investigated the experience of Aboriginal and/or Torres Strait Islander parents and carers in accessing disability support for their child(ren) (aged 0-8). Given the importance that participants placed on the community for accessing resources and information, greater investment in raising community education and awareness concerning disability services was identified as a strategy to favourably impact access to services and support. Participants also indicated that they benefitted from, and thus preferred a, holistic 'one-stop' model where a variety of practitioners work in-concert to provide disability services and support. In many instances, this model of service provision was delivered via local Aboriginal Community Controlled Health Organisations (ACCHOs). These findings highlight the importance of considering the costs associated with - (i) raising community awareness around disability services, and (ii) the provision of holistic integrated health-care delivery models offered locally - when measuring the cost of disability for indigenous people. 
The dearth of research investigating the cost of disability for Indigenous people may be adversely impacting the health and social care programs offered to Indigenous people with disability. Research in the area is essential as it will provide an evidence base to support policy decisions informing, and resources required to provide, effective disability health and social support services for Indigenous people. Recent studies measuring disability cost have done so via the use of an adapted tool - i.e. the Client Service Receipt Inventory (CSRI) (Beecham \& Knapp, 1992) - alongside the measurement of additional costs associated with the provision of health and social support services including government costs and home and community care costs (Doran et al., 2012), care facility costs (Knapp, Comas-Herrera, Astin, Beecham, \& Pendaries, 2005), outpatient visit costs (Minh, Giang, Liem, Palmer, Thao, \& Duong, 2015), and the cost of care provided by family (Strydom, Romeo, Perez-Achiaga, Livingston, King, Knapp, \& Hassiotis, 2010). While the suggested costs are likely to be relevant, in the future, methodologies utilised to establish the cost of disability among Indigenous people would benefit from measuring the cost of providing the five considerations identified throughout DiGiacomo et al. (2013) and Green et al. (2016).

\section{Conclusion}

It is expected that Indigenous people experience asymmetric disability costs compared to non-Indigenous people and the lack of research in the area is concerning. Distinct costs for providing health and social support to Indigenous people with disability are underpinned by costs of providing culturally appropriate services, integrated services, and raising community awareness. It is important that future studies that aim to establish the cost of disability among Indigenous people account for these considerations. Furthermore, such studies are imperative as they can favourably inform health and social care services offered for Indigenous people with disability, and furthermore, contribute towards their receipt of positive health outcomes. 


\section{References}

Angell, B. J., Muhunthan, J., Irving, M., Eades, S. \& Jan, S. (2014). Global systematic review of the cost-effectiveness of indigenous health interventions. Plos One, 9, e111249-e111249.

Antón, J.-I., Braña, F.-J., \& Muñoz de Bustillo, R. (2016). An analysis of the cost of disability across Europe using the standard of living approach. SERIES, 7, 281306.

Australian Government. (2014). Report on GST Revenue Sharing Relativities. 2014 Update. Canberra.

Avery, S. (2016). 'Living our Ways': A community-driven research program to understand the intersection of rights for Indigenous people with disability. The Lowitja Institute International Indigenous Health and Wellbeing Conference 2016. Melborune, Australia.

Beecham, J., \& Knapp, M. (1992). Costing psychiatric interventions. In: THORNICROFT, G., BREWIN, C. \& WING, J. (eds.) Measuring Mental Health Needs. London: Gaskell.

Berthoud, R. (1991). Meeting the costs of disability. In: DALLEY, G. (ed.) Disability and social policy. London: Policy Studies Institute.

Biddle, N., Al-Yaman, F., Gourley, M., Gray, M., Bray, J. R., Brady, B., ... \& Montaigne, M. (2012). Indigenous Australians and the National Disability Insurance Scheme: the extent and nature of disability, measurement issues and service delivery models. Canberra, Commonwealth of Australia.

Biddle, N., Al-Yaman, F., Gourley, M., Gray, M., Bray, J. R., Brady, B., ... \& Montaigne, M. (2014). Indigenous Australians and the National Disability Insurance Scheme (p. 176). Canberra, ANU Press \& Centre for Aboriginal Economic Policy Research.

Brouwer, W., Rutten, F. \& Koopmanschap, M. (2001). Costing in economic evaluation. In: DRUMMOND, M. F. \& MCGUIRE, A. (eds.) Economic evaluation in health care: merging theory with practice. USA: Oxford University Press.

Browne, C. V., Mokuau, N., Ka'opua, L. S., Kim, B. J., Higuchi, P. \& Braun K. L. (2014). Listening to the voices of native Hawaiian elders and 'ohana caregivers: discussions on aging, health, and care preferences. Journal of Cross-Cultural Gerontology, 29, 131-151.

Castleden, H., Morgan, V. S., \& Lamb C. (2012). "I spent the first year drinking tea": Exploring Canadian university researchers' perspectives on community- based participatory research involving Indigenous peoples. The Canadian Geographer / Le Géographe canadien, 56, 160-179.

Dew, A., Bulkeley, K., Veitch, C., et al. (2013). Carer and service providers' experiences of individual funding models for children with a disability in rural and remote areas. Health \& Social Care in the Community, 21(4), 432-441.

DiGiacomo, M., Davidson, P. M., Abbott, P., et al. (2013a). Childhood disability in Aboriginal and Torres Strait Islander peoples: a literature review. International Journal For Equity In Health, 12:7, 1-18.

DiGiacomo, M., Delaney, P., Abbott, P., Davidson, P. M., Delaney, J., \& Vincent, F. (2013b). 'Doing the hard yards': carer and provider focus group perspectives of accessing Aboriginal childhood disability services. BMC health services research, 13, 326-326.

Doran, C. M., Einfeld, S. L., Madden, R. H., Otim, M., Horstead, S. K., Ellis, L. A., \& Emerson, E. (2012). How much does intellectual disability really cost? First 
estimates for Australia. Journal of Intellectual and Developmental Disability, 37, 42-49.

Durey, A., Wynaden, D., Thompson, S. C., Davidson, P. M., Bessarab, D., \& Katzenellenbogen, J. M. (2012). Owning solutions: a collaborative model to improve quality in hospital care for Aboriginal Australians. Nursing Inquiry, 19, 144-152.

Durst, D., Gay, A., \& Morin, G. (2006). Urban aboriginal families of children with disabilities: social inclusion or exclusion. National Association of Friendship Centres. http://www. nafc-aboriginal. com/PDF/NAFCDisability-17-03-06. pdf.

Elder, H. (2013). Te Waka Oranga: An indigenous intervention for working with Māori children and adolescents with traumatic brain injury. Brain Impairment, 14(3), 415-424.

Government of Canada. (2011). Status of Remote/Off-Grid Communities in Canada. Canada.

Green, A., Abbott, P., Delaney, P., Patradoon-Ho, P., Delaney, J., Davidson, P. M., \& DiGiacomo, M. (2016). Navigating the journey of Aboriginal childhood disability: a qualitative study of carers' interface with services. BMC Health Services Research, 16, 680-680.

Haynes, E., Taylor, K. P., Durey, A., Bessarab, D., \& Thompson, S. C. (2014). Examining the potential contribution of social theory to developing and supporting Australian Indigenous-mainstream health service partnerships. International journal for equity in health, 13, 75-75.

Isaacs, A. N., Pyett, P., Oakley-Browne, M. A., Gruis, H., \& Waples-Crowe, P. (2010). Barriers and facilitators to the utilization of adult mental health services by Australia's Indigenous people: Seeking a way forward. International Journal of Mental Health Nursing, 19, 75-82.

Knapp, M., Comas-Herrera, A., Astin, J., Beecham, J., \& Pendaries C. (2005). Intellectual disability, challenging behaviour and cost in care accommodation: what are the links? Health \& Social Care in the Community, 13, 297-306.

Larkins, S. L., Geia, L. K., \& Panaretto, K. S. (2006). Consultations in general practice and at an Aboriginal community controlled health service: do they differ? Rural and remote health, 6, 560 .

Mcdonald, D., Lakhani, A., \& Zeeman, H. (2016). Ethics of time: Ensuring effective relational communication with NDIS participants who have intellectual disabilities. Journal of Intellectual Disability Research, 60(7), 706.

Maclennan, B., Wyeth, E., Davie, G., Wilson, S., \& Derrett S. (2014). Twelve-month post-injury outcomes for Māori and non-Māori: findings from a New Zealand cohort study. Australian And New Zealand Journal Of Public Health, 38, 227-233.

Minh, H. V., Giang, K. B., Liem, N. T., Palmer, M., Thao, N. P., \& Duong, L. B. (2015). Estimating the extra cost of living with disability in Vietnam. Global Public Health, 10, S70-9.

Mitchell, F. (2015) Facilitators and barriers to informed choice in self- directed support for young people with disability in transition. Health \& Social Care in the Community, 23, 190-199.

Moher, D., Liberati, A., Tetzlaff, J., Altman, D. G., Group, P., \& for the P. G. (2009). Preferred reporting items for systematic reviews and meta-analyses: the PRISMA statement. BMJ: British Medical Journal, 339, 332-336.

Panaretto, K. S., Wenitong, M., Button, S., \& Ring I. T. (2014). Aboriginal community controlled health services: leading the way in primary care. The Medical journal of Australia, 200, 649. 
Parliament of Australia. (2013). National Disability Insurance Scheme Act 2013. Parliament of Australia.

Productivity Commission. (2011). Disability care and support.

Purdie, N., Dudgeon, P., \& Walker, R. (2010). Working together: Aboriginal and Torres Strait Islander mental health and wellbeing principles and practice. West Perth, WA, Kulunga Research Network.

Reading, C. L., \& Wien F. (2009). Health Inequalitites and Social Determinants of Aboriginal Peoples Health. National Collaborating Centre for Aboriginal Health.

Reading, J. L., Kmetic, A., \& Gideon V. (2007). Assembly of First Nations: Discussion paper for the World Health Organization commission on social determinants of health. Ottawa, Canada: Assembly of First Nations.

Sen, A. (2004). Disability and Justice. Disability and Inclusive Development Conference. The World Bank, Washington D.C.

Strydom, A., Romeo, R., Perez-Achiaga, N., Livingston, G., King, M., Knapp, M., \& Hassiotis A. (2010). Service use and cost of mental disorder in older adults with intellectual disability. The British Journal Of Psychiatry: The Journal Of Mental Science, 196, 133-138.

Vos, T., Barker, B., Begg, S., Stanley, L., \& Lopez A. D. (2009). Burden of disease and injury in Aboriginal and Torres Strait Islander Peoples: the Indigenous health gap. International Journal Of Epidemiology, 38, 470-477.

World Health Organization [WHO]. (2011). World report on disability.

Zhao, Y., Condon, J. R., Guthridge, S., \& You, J. (2010). Living longer with a greater health burden--changes in the burden of disease and injury in the Northern Territory Indigenous population between 1994-1998 and 1999-2003. Australian And New Zealand Journal Of Public Health, 34 Suppl 1, S93-S98.

Zhao, Y., Guthridge, S., Magnus, A., \& Vos, T. (2004). Burden of disease and injury in Aboriginal and non-Aboriginal populations in the Northern Territory. The Medical Journal Of Australia, 180, 498-502. 


\section{Biographical Notes}

Dr Ali Lakhani is a Research Fellow with the Hopkins Centre, Menzies Health Institute Queensland and his research focuses on (i) the intersection between the environment and health, (ii) culturally appropriate research methods, (iii) and arts participation and health and wellbeing. He is currently managing segments of two Australian Research Council Linkage Projects: (i) Developing and testing a decision system for identifying housing options, mapping preferences and evaluating priorities in the disability market, and (ii) Farming 4 Care: Using nature to cultivate resilience in young people.

Jennifer Cullen is an Adjunct Associate Professor and CEO of Synapse in Queensland and NSW. Jennifer has over 26 years' experience in disability and aged care services and was appointed in 2013 to the NDIS Independent Advisory Council as the Queensland Member and was appointed in 2016 to the National Disability and Carers Advisory Council as a Member. She leads a range of research and projects that focus on supporting Indigenous Australians with complex neurocognitive disabilities, including FASD. Jennifer is a descendant of the Wakka Wakka people.

Dr Clare Townsend is the National Manager-Research and Development at Synapse and Adjunct Associate Professor at Griffith University and James Cook University. She is Chief Investigator on a suite of research projects which aim to improve identification and understanding of neurocognitive disabilities amongst Aboriginal and Torres Strait Islander peoples in Queensland and Victoria. This work includes the Guddi project research with homeless people in Cairns. She is also a Partner Investigator on an ARC Linkage Grant that prioritises the access and development of housing options for people with a disability. She has a background in mental health policy research, service provision and has undertaken research in the area of complex intellectual disability and quality of life. 